\title{
ÉTICA E INFINITO EM HUSSERL
}

Alberto Marcos Onate *

RESUMO - Avaliar o alcance de seu próprio projeto fenomenológico sempre foi motivo de preocupação filosófica para Husserl. Talvez por isso, ele nunca tenha cessado de reformular seus conceitos e suas teorias, visando a um grau cada vez maior de profundidade. Tal interesse pelos limites da fenomenologia husserliana prossegue na atividade de seus intérpretes. Neste artigo, pretende-se apresentar e discutir algumas dessas leituras, procurando-se realçar que a estratégia de privilegiar componentes éticos para pensar os limites da fenomenologia de Husserl não constitui alternativa fecunda. A discussão deve privilegiar parâmetros ontológicos, a partir da abordagem de conceitos-chave corretamente selecionados, em especial os conceitos de infinito e de presente vivo.

PALAVRAS-CHAVE - Husserl. Fenomenologia. Ética. Infinito. Presente vivo.
ABSTRACT - Assessing the scope of his own phenomenological project was always of philosophical concern to Husserl. Perhaps because of this, he has never ceased to reformulate his concepts and theories, aimed at an ever greater degree of depth. This interest by the limits of Husserlian phenomenology continues in the activity of his interpreters. This article intends to present and discuss some of these readings, trying to stress that the strategy of favouring ethical components to think the limits of Husserl's phenomenology is not a fruitful alternative. The discussion should favour ontological parameters, based in the approach of key concepts correctly selected, especially the concepts of infinite and living present.

KEYWORDS - Husserl. Phenomenology. Ethics. Infinite. Living present.

\section{Introdução}

Adotando-se como ponto de partida o artigo de Husserl Filosofia como ciência rigorosa, publicado na revista Logos, em 1911, trata-se de investigar o alcance do programa fenomenológico ali apresentado. Duas tendências de pensamento são criticadas no texto programático de 1911, em vista da liberação do terreno à filosofia como ciência estrita: o naturalismo e o historicismo. O primeiro é caracterizado, sobretudo, pela naturalização da consciência e das idéias, em que aquela

* Professor de Filosofia.

\begin{tabular}{|l|l|l|l|l|l|}
\hline VERITAS & Porto Alegre & v. 54 & n. 2 & maio/ago. 2009 & p. 172-186 \\
\hline
\end{tabular}


é entendida como suporte de operações mentais e essas são encaradas como operações representativas do mundo natural, ambas passíveis de abordagem experimental. O segundo baseia-se em uma consciência histórica que capta as várias cosmovisões inerentes às diferentes épocas, numa articulação dos componentes nucleares de cada cultura, visando a afrontar os enigmas do mundo e da vida. Como traço comum das orientações naturalista e historicista, Husserl diagnostica o relativismo e o ceticismo, incompatíveis com a busca da filosofia verdadeiramente científica.

O motivo de tais limitações diz respeito a que elas operam em consonância a fatos e não a idéias ou essências. Uma filosofia que se pretenda científica deve efetivar-se desde o fundamento, desde uma ausência radical de pressupostos que lhe permita apreender e articular princípios absolutamente claros. A chave para isso concerne à apreensão dos fenômenos tais como se dão, enquanto meros fenômenos, possibilitando uma contemplação imediata de suas essências. Quando captadas pela intuição pura, as essências não se subordinam a determinações naturais ou históricas, mas remetem a âmbitos peculiares de experiência que se podem designar de fenomenológicos. Cabe investigar qual o estatuto e, sobretudo, qual o alcance do essencialismo vinculado por Husserl à noção de filosofia científica. Se, por um lado, como reitera o pensador alemão, a visão de essências não implica em nada de místico ou obscuro, por outro, os meandros dessa visibilidade essencial demandam sempre novos esforços de apreensão e de exposição. Quais os caminhos que conduzem ao cerne do campo essencial? Qual o perímetro, se houver um e se ele for apreensível, do campo essencial? No fim das contas, pode a filosofia, enquanto empreendimento descritivo de essências, tornar-se ciência estrita de maneira completa? Quais os critérios de verificação de tal completitude?

1. No artigo de 1911, o pensador alemão considera que em nenhum momento de sua história a filosofia alcançou o necessário grau científico, embora desde seus primórdios tenha almejado tal nível de rigor ${ }^{1}$. Mais do que isto, nem mesmo a cabal clarificação do estatuto de cientificidade foi alcançado. A proverbial afirmação kantiana de que não se pode ensinar filosofia, mas apenas ensinar a filosofar, equivaleria a uma assunção do fracasso científico do discurso filosófico. Fracasso que não seria parcial, fruto de imperfeições metódicas ou de conteúdo, constituindo antes uma restrição global, uma ausência absoluta de caráter científico.

1 Com exceção do movimento romântico, sobretudo na obra hegeliana, elaborada em consonância a uma adulteração do afã científico. 
Diante de panorama tão desolador, como proceder? Conformar-se ou tentar revigorar o esforço consciente de ciência estrita para a filosofia? A segunda alternativa é a opção resoluta de Husserl, implicando em recomeçar tudo desde um fundamento absolutamente seguro, condição sine qua non da empreitada científica.

Para tanto, exige-se a adoção de uma postura simultaneamente antinaturalista e antihistoricista que logre realizar uma autêntica crítica da razão, crítica de caráter positivo alicerçada na intuição e na descrição de essências, de idéias. Cientificidade, essencialismo e idealismo são indissociáveis para Husserl, e constituem um só âmbito irredutível ao campo fatual, empírico. A pretensão de naturalizar ou de historicizar as idéias significa arruinar já em seu começo todo projeto científico. Consideração radical que leva o pensador alemão a afirmar no artigo programático de 1911: "Enquanto se mantenha pura e se abstenha da posição existencial da natureza, a fenomenologia pura considerada como ciência não pode ser mais que uma investigação de essência e de modo nenhum uma investigação de existência" (Husserl, 1987, p. 36).

2. Tal obsessão pelo científico e pelo ideal desfrutou de decisiva fortuna crítica entre os intérpretes da obra husserliana. Dois textos merecem atenção, pela instigante controvérsia no tratamento do tema. Em 1917, Léon Chestov publica o artigo Memento mori, ${ }^{2}$ marcado já no título ${ }^{3}$ por um afastamento em relação às pretensões husserlianas. Chestov interpreta "A filosofia como ciência estrita" a partir das noções de filosofia e de sabedoria. Normalmente reunidas ou ao menos aproximadas ao longo da história do pensamento ocidental, elas se separam decisivamente na concepção de Husserl. Falta à sabedoria a apreensão do fundamento, que só a filosofia científica pode alcançar. Nesta empreitada, a gnosiologia assume o papel de condutora, privilegiando a pergunta acerca dos modos de compreensão dos princípios e das causas de todo fenômeno. Problemas gnosiológicos estritos não se confundem com problemas psicológicos, dado o caráter transcendental dos primeiros e o estatuto natural dos segundos.

2 Traduzido do russo para o francês por Boris de Schloezer, em 1926. O texto deu origem a uma importante polêmica com Jean Hering, autor do artigo "Sub specie aeternitatis", no qual defende a posição husserliana, rebatido por Chestov no artigo "Que é a verdade?". Dados os limites teóricos propostos no presente texto, não se tratará de tais desdobramentos polêmicos. Vários outros textos e comentadores poderiam exemplificar a leitura da obra husserliana que aqui me interessa destacar. A escolha se deve à antiguidade do artigo, mostrando que tal leitura, com variantes pontuais, mostra-se persistente e atual.

3 "Lembrança da morte". 
Desenvolve-se uma confiança inabalável na capacidade racional, cujos alicerces encontram-se em uma original teoria das idéias. O âmbito ideal funciona enquanto condição de possibilidade de todo conhecimento objetivo, excluindo-se dele qualquer posição metafísica. A atividade da razão, entendida em sentido amplo, dispensa toda justificação ulterior, sendo ela que pode, desde si própria, tudo justificar. Para Chestov, a filosofia husserliana é rigorosamente excludente: "Tudo ou nada. Ou bem a evidência é a meta a que tende o pensamento humano quando procura a verdade, e tal evidência pode ser obtida por procedimentos humanos, ou bem o caos, a loucura se estabelecerão sobre a terra e será permitido, a quem tiver fantasia, apoderar-se dos direitos da razão, de seu cetro, de sua coroa" (Chestov, 1926, p. 33). Admitida a primazia da razão autônoma, a realidade fatual, mundana, recua para segundo plano. Implanta-se a soberania ilimitada das operações racionais, aptas a iluminar estruturalmente a ocorrência de todo fenômeno.

Chestov reconhece que não se pode lutar contra Husserl em seu próprio território ideal. A investigação deve dirigir-se antes ao alcance do idealismo fenomenológico, tarefa na qual se detecta nele uma lacuna decisiva: a desconsideração da gênese empírica do conhecimento e a falta de esclarecimento dos vínculos entre o empírico e o a priori. O interesse fenomenológico consiste unicamente em descrever as estruturas do conhecimento, a relação intrínseca das leis e dos objetos ideais mediante os quais a atividade racional conduz à apreensão da verdade. Cabe, porém, indagar com Chestov: "Pode-se separar o enfoque gnosiológico do psicológico? Por que as teorias do conhecimento, ou melhor, os apologistas da teoria do conhecimento evitam tão ciosamente todas as demandas de esclarecimentos genealógicos?... Qual é, pois, a relação entre as verdades de razão, as verdades ideais e o mundo real? Já que as idéias são, já que elas possuem seu ser próprio, por que elas se preocupariam com os outros gêneros de existência?" (Chestov, 1926, p. 23). Embora se reconheça o vigor do projeto racionalista husserliano, tais restrições limitam decisivamente o âmbito de sua exeqüibilidade.

De sua parte, para contrabalançar este ultra-racionalismo, Chestov defende um testimonium paupertatis, uma assunção esclarecida dos limites nos quais pode operar a razão com suas verdades a priori. Resgatase o principal desiderato atribuído por Platão a todo filósofo: prepararse para a morte. $O$ espectro da finitude ronda sempre as veredas que anseiam o infinito, inclusive aquelas marcadas pela racionalidade mais pura. Não seriam o psicologismo, o naturalismo, e o relativismo inerente a ambos, em todas as suas implicações, a expressão do memento mori, que persiste na luta contra a tirania da razão, mesmo transcendentalmente fundada? Chestov é contundente ao afirmar que "O mais difícil para o 
homem é renunciar à idéia de que sua verdade é e deve ser verdadeira para todos. E, todavia, é preciso se separar desta verdade" (Chestov, 1926, p. 47). Por trás da aparente defesa de um solipsismo exacerbado, trata-se de uma salutar desconfiança em relação a todas as empreitadas infinitas, entre as quais a husserliana, que parecem contrariar inclusive o preceito capital da própria fenomenologia: considerar tudo que nos é dado enquanto fenômeno apenas nos limites de sua doação (Husserl, 2006, p. 69).

3. Atenta à importância do tema, Carola Barbero aborda-o diretamente no artigo Il problema dell'infinito nella fenomenologia di Husserl (2000). Assume-se que o conjunto da reflexão husserliana encontra-se sob os auspícios da tentativa de realização da filosofia como ciência estrita, visando à compreensão tanto da origem do sentido quanto do sentido da origem. O desafio condutor é o esclarecimento das relações entre ideal e real, lógica e experiência, transcendental e empírico, ciência e fato. Husserl retoma a empreitada kantiana, reformulando seus meandros: o vínculo entre transcendental e empírico não é mediado pelo esquema, mas pela idéia, que opera através de regras e não de imagens. A fenomenologia apresenta-se como ciência da possibilidade, na qual o conceito de horizonte é decisivo. O horizonte da idéia só pode ser intuído de modo negativo, inadequado, ampliando ao infinito o trabalho de objetivação. A idéia se caracteriza enquanto tarefa, meta de todo esforço objetivante, funcionando no papel de estímulo e regra de nosso proceder cognoscitivo.

O infinito da idéia se oferece de maneira inadequada, embora evidente. O infinito que se dá é atual, porém sua atualidade difere essencialmente daquela do infinito propriamente ideal. O infinito se manifesta no finito apenas em sua potencialidade. Barbero detecta quatro formulações básicas de infinito ao longo da obra husserliana: nas Investigações Lógicas, como vir-a-ser infinito da lógica; em Idéias I, como totalidade infinita da experiência temporal; em Experiência e juízo, como mundo considerado enquanto solo infinito da experiência possível; em Meditações Cartesianas e Krisis, como teleologia intencional. O que há de comum em todos os desdobramentos expositivos analisados é que:

A idéia de infinito é, com efeito, um conceito operatório, ou seja, tem um sentido na medida em que cumpre uma função (no caso, reguladora), e não por si mesma. Isto implica que a negatividade do infinito husserliano, entendido como infinito não-cumprimento (que é, porém, sempre contemporaneamente um indefinido cumprimento), inclua a positividade de uma tarefa: a idéia de infinito inclui, com efeito, uma positividade axiológica e teleológica que define os contornos de uma ética do pensamento (Barbero, 2000, p. 4). 
O filósofo, no papel de funcionário da humanidade, é o responsável por buscar continuamente a realização da idéia no mundo dos fatos. Ele é conduzido no percurso por uma fé problemática, que se afasta tanto do dogmatismo quanto do relativismo, subordinando-os ao entusiasmo pela grandeza do objetivo infinito. A incompletude das realizações inerentes à tarefa não deve ser encarada como malogro do esforço infinito, mas enquanto conquista sempre renovável. O que importa na construção da filosofia enquanto ciência estrita é o exemplo da meta almejada, guia e sustentáculo das diligências a ela orientadas "como se" (als ob) fosse possível realizá-la.

Após interpretar pontualmente os principais textos de Husserl a partir da idéia de infinito, Barbero caracteriza-a como pólo de intenção puro, possibilidade reguladora do aparecer e da certeza finita, consoante uma determinabilidade indefinida. Ela é "O trâmite de uma relação: sem ela a fenomenologia se resolveria em um solipsismo e a objetividade seria impossível, o cogito não pensaria o mundo e a história, mas pensaria apenas a si mesmo, e a intencionalidade se resolveria em um jogo sem significado" (Barbero, 2000, p. 32). Para compreender-se o estatuto infinito da idéia, deve-se distinguir meticulosamente intenção e intuição, pois o âmbito possibilitador de toda intuição não pode, a rigor, ser intuído, apenas visado intencionalmente. A fenomenologia está condenada a não tematizar sua própria origem, diferindo-a em progressivas aproximações incompletas de conteúdo, embora evidentes regulativamente. O infinito em sua função reguladora diz-se no modo da história, sem circunscrever-se à finitude dada, por remeter sempre ao horizonte de sentido que possibilita a constituição desta. "O mérito de Husserl reside propriamente em ter individuado um a priori concreto que se pudesse viver no modo do horizonte" (Barbero, 2000, p. 34). O nexo entre infinito e indefinido, inerente à idéia, explicita-se no ziguezague da história enquanto potencialidade infinita concreta, âmbito por excelência no qual coincidem o a priori e o teleológico.

As leituras de Chestov e Barbero, cujos itinerários são respectivamente extrínsecos e intrínsecos ao discurso propriamente husserliano, desembocam em considerações éticas para complementar ou legitimar as teses fenomenológicas do pensador alemão ${ }^{4}$. O programa fenomenológico husserliano só se consumaria apelando a uma dimensão ética de caráter aberto e sempre atualizável. Visando a aquilatar-se a pertinência e o alcance de tais interpretações, faz-se necessário investigar o sentido

4 Em seu artigo "Husserl interprete di Kant", de 2005, Angela Ales Bello também encaminha a sua interpretação do pensamento husserliano em uma chave ética, acrescentando-lhe, porém, componentes religiosos. 
pontual das noções de finito, infinito e horizonte na obra husserliana, circunscrevendo-se a abordagem, dados os limites de uma exposição articular, aos três volumes de Idéias, sobretudo ao primeiro e ao terceiro, textos paradigmáticos no tocante à elaboração do programa fenomenológico em seu conjunto.

4. $\mathrm{Na}$ "atitude" ${ }^{5}$ natural, comandada pelas determinações espáciotemporais, tem-se um mundo disponível à percepção. No campo perceptivo vigente, além dos objetos visados diretamente, vigora um campo perceptivo pontual que compreende outros objetos distribuídos em graus variados de determinação e indeterminação, desde o nível de vacuidade até o nível de plenitude. Ampliando-se a consideração temática, nota-se que o campo perceptivo enquanto tal implica um horizonte infinito de obscuridades e claridades coordenadas pela atenção. As progressões e regressões constitutivas do horizonte efetivam-se em consonância a estruturas concordantes ou dissonantes sempre renováveis, mas estabelecidas intrinsecamente em seus parâmetros de atuação, em uma cadeia infinda de nexos de efetividade. Parâmetros detectáveis, mutatis mutandis, também no âmbito temporal. Todo presente remete, por essência, a passados e futuros possíveis continuamente permeáveis à compreensão, em um perene esforço clarificador. Sucedem-se graus infinitamente variados de distinção e indistinção, de conhecimento e desconhecimento, de vivacidade e debilidade dos momentos visados.

Decorre disso que toda percepção de coisa implica essencialmente em certa inadequação, captando-se, a cada vez, apenas um de seus perfis ou um grupo deles. Por mais perfeita que seja uma visada, ela não esgota em seus enquadramentos o objeto material em foco, remetendo, de maneira necessária, a um horizonte de indeterminação aberto a apreensões de acordo com os diferentes modos de doação objetiva. Instaura-se um jogo infinito de claro-obscuro que, no cômputo geral, aponta a uma progressão compreensiva do objeto apresentado. Mais do que mero acúmulo de perfis apropriados e inapropriados do que se apresenta, trata-se de nexos contínuos de unidade de sentido sistematicamente regulados e interligados. Tal conexão, entretanto, por mais rigorosa e ampla que seja, comporta sempre novas aberturas, novos perfis a serem explorados.

5 Em alemão, Einstellung. O tradutor brasileiro de Idéias I, Márcio Suzuki, preferiu o vocábulo "orientação", sem fornecer argumentos lingüísticos e filosóficos mais detalhados para tal opção. Outras alternativas seriam "posição", "sintonia", "ajuste", conforme indicação feita por Celso Braida em diálogo com o autor deste artigo. Por ora, mantém-se a versão tradicional de "atitude", pedindo ao leitor que desconsidere a carga subjetiva normalmente associada ao termo. 
Outros nexos possíveis sempre aguardam, de maneira essencial, seus preenchimentos.

Entre os propósitos condutores da fenomenologia husserliana em seu conjunto encontra-se justamente o de domesticar racionalmente, mediante recursos metódicos eficazes, o espectro do horizonte perceptivo. O método privilegiado das sucessivas e paulatinamente mais radicais reduções eidéticas e fenomenológicas abre "um campo de conhecimentos eidéticos... um campo por toda parte infinito. A diversidade das espécies e formas de vivido, com suas composições eidéticas reais e intencionais, é mesmo inesgotável e, por conseguinte, também o é a diversidade de nexos nelas fundados e de verdades apoditicamente necessárias" (Husserl, 2006, p. 143). Tanto o método de acesso quanto a investigação dos conteúdos inerentes ao âmbito que Husserl denomina de "campo infinito do a priori da consciência" divergem daqueles concernentes ao infinito natural perceptivo: nesses, os dados se apresentam de modo familiar, sendo o desconhecido apenas horizonte de algo conhecido; naqueles, por se tratar de um território ainda não legitimado no que lhe é próprio, o estabelecimento do horizonte carece de referenciais e demanda uma confiança inusitada no acerto das diferentes vias escolhidas para explorá-lo de maneira cabal.

Exploração na qual a questão do tempo desfruta de papel privilegiado. Em vez do tempo objetivo, cósmico, modalmente fixado em passado, presente e futuro, deve-se investigar o tempo fenomenológico, supérstite à purificação consumada pelas reduções eidéticas e propriamente fenomenológicas. O tempo fenomenológico, enquanto forma necessária de vinculação entre vividos do eu puro, implica um fluxo que, a rigor, não começa nem finda, contrariamente ao vivido individual que se subordina à duração, ou seja, a começo e fim. No fluxo temporal fenomenológico ocorre exclusivamente a interligação unificadora dos diferentes horizontes do antes, do depois e do simultâneo, a partir do ponto-limite da protoimpressão que remete a horizontes infinitos de retenção e protenção. $\mathrm{Na}$ cadeia progressiva de apreensões temporais, apreende-se também a unidade do fluxo de vividos, podendo-se considerá-la como idéia no sentido kantiano: incondicionado que não pode ser conhecido, apenas pensado. Embora o conteúdo do fluxo não possa ser determinado e apreendido de maneira peremptória, pode-se de modo legítimo percorrer idealmente o seu perímetro. Decorre disso que a compreensão plena de qualquer vivido individual dependa do meio ideal no qual ele se insere, a partir de um encadeamento rigoroso de remissões mútuas.

Para cumprir integralmente o seu papel, a fenomenologia transcendental deve considerar os vividos não como meros complexos de conteúdo, mas como elementos intencionais que, mediante suas doações 
de sentido, prescrevem eideticamente todas as ocorrências múltiplas de consciência de algo. Perspectiva investigadora que não se resume a reunir componentes eidéticos dispersos, constituindo antes tarefa sistemática:

É preciso estudar sistematicamente e tornar evidente, em generalidade eidética, todas as espécies fundamentais de consciência possível e as alterações que delas fazem essencialmente parte, as fusões, as sínteses; é preciso estudar como prescrevem, mediante sua essência própria, todas as possibilidades (e impossibilidades) de ser, como por leis de essência absolutamente firmes o objeto existente é correlato de nexos de consciência de conteúdo eidético bem determinado, assim como, inversamente, o ser de nexos de tal espécie é equivalente ao objeto existente; e isso sempre com referência a todas as regiões de ser e a todos os níveis de generalidade, descendo até a concreção do ser. (Husserl, 2006, p. 198-199).

Independentemente do âmbito de generalidade ou de particularidade da abordagem, na esfera dos vividos transcendentais, "tudo está prescrito eideticamente" (Husserl, 2006, p. 299). Husserl refere-se a um "sistema eidético", no qual se articulam de maneira rigorosa todos os membros ideais efetivos e possíveis, cabendo à investigação fenomenológica trazê-lo à luz clarificadora do conhecimento absoluto. Para cada categoria de apreensão, cujo correlato é cada categoria de objeto, estão prescritas eideticamente com precisão quais configurações apreensivas, perfeitas ou imperfeitas, são possíveis aos objetos inerentes a tal categoria. Também idealmente, está prescrita a cada apreensão incompleta como ela pode alcançar a perfeição, enriquecendo-se e preenchendo-se na intuição. De modo similar, cada categoria de objeto estipula regras precisas à plena determinação do sentido e da maneira de doação dos objetos a ela subordinados, prescrevendo as regras gerais evidentes para cada tipo de objetos perfilados nos vividos intencionais.

Mesmo os objetos transcendentes, componentes do mundo empiricamente dado, embora essencialmente impermeáveis à determinação e intuição completas, submetem-se a um contínuo de aparições prescrito em plena legalidade eidética, enquanto sistema absolutamente determinado de processos infinitos de doação. Husserl denomina-o de "contínuo infinito onidirecional", constituído pelo mesmo $X$ determinável segundo fases coerentes e progressivas. O tipo próprio de intuição desse contínuo é puramente ideal, enquanto conjunto de regras a priori para a passagem legítima da imperfeição à plena perfeição no campo infinito da doação. Para dar conta do progresso em direção ao dado perfeito, a atividade do contínuo infinito implica uma investigação equivalente e concomitante dos processos de deslegitimação e mesmo de infirmação de alguns ou de todos os eventos eideticamente considerados. É tal nível de abrangência 
que permite ao pensador alemão asseverar que "A fenomenologia não se detém, por princípio, em um linguajar vago, em generalidades obscuras, ela exige clarificação, análise e descrição sistemáticas precisas, que penetrem nos nexos eidéticos e até nas particularizações últimas deles: ela exige trabalho concludente" (Husserl, 2006, p. 333).

Racionalidade total e sistematicidade, condutoras também da exposição presente no terceiro volume de Idéias, no qual se caracteriza a fenomenologia como "... a tarefa universal e o ideal mais abrangente, embora situado no infinito: captar na intuição e na clareza mais acabadas, numa integralidade sistemática, o mundo das idéias, o mundo das espécies de essências possíveis das objetidades possíveis, quaisquer que sejam..." (Husserl, 1971, p. 104). Parece não haver limites infranqueáveis à plena visada fenomenológica, desde que encaminhada metodicamente de maneira pertinente. Enquanto programa filosófico, o idealismo e o essencialismo husserlianos operam no infinito, mas não se dobram a ele. Ao radicalizar os processos reflexivos e redutivos, a fenomenologia mostra-se deveras confiante em alcançar a infinitude, descrevendo o conjunto das estruturas constitutivas de qualquer mundo possível.

Husserl sabe dos obstáculos teóricos a enfrentar, das inevitáveis mudanças de rumo nas investigações, dos aprofundamentos sempre reiterados, mas não esmorece: "Subsistem aqui dificuldades centrais, e não se pode antever em que medida serão solucionadas ... Infinitudes, portanto, subsistem para o conhecimento, desde que ele sempre esteja pronto para encetar novas direções. Mas, não subsiste nenhuma infinitude em si. E, se não há uma tal infinitude, uma apreensão fechada da coisa tem de ser possível. Isso ainda precisa ser refletido, desenvolvido, discutido de maneira mais determinada" (Husserl, 2006, pp. 381-382). Na empreitada husserliana, óbices convertem-se em desafios, retomadas tornam-se estímulos para novas conquistas, esforços finitos transformam-se em tarefas infinitas. Diante de tal confiança irrestrita do pensador alemão no alcance da racionalidade, cabe indagar, por um lado, se a derivação ética requerida pelos intérpretes antes mencionados é pertinente e, de outro lado, averiguar se o método e os conceitos husserlianos tornam exequível o cumprimento de seu sistema ideal.

5. No tocante ao complemento ético reivindicado pelos intérpretes, ilustrado acima pelos enquadramentos extrínsecos e intrínsecos de Chestov e Barbero, ambos parecem derivar de uma chave kantiana de compreensão do projeto husserliano, atribuindo-lhe uma insuficiência teórica a ser compensada, dentro de certos limites, pela empreitada ética, tal como fizera Kant na passagem da primeira à segunda Crítica. O emprego maciço por Husserl da expressão "idéia em sentido kantiano" 
para caracterizar os horizontes abordados pela fenomenologia parece favorecer tal interpretação. Porém, em uma análise mais detida, detectase que a expressão husserliana concerne antes à ênfase no caráter estritamente ideal, não-efetivo, dos elementos e das conexões inerentes a cada horizonte explorado pela visada fenomenológica. Além de não comportarem tais implicações éticas, os componentes e nexos ideais formulados por Husserl perdem também o estatuto de incondicionados em sua versão kantiana. Eles próprios devem se dobrar à visada fenomenológica, sob pena de o projeto racional malograr já em seus pressupostos, como foi o caso paradigmático kantiano.

Embora se possam extrair fecundas conseqüências éticas do programa fenomenológico husserliano, sua instauração intrínseca é de cunho basicamente teórico, num processo sucessivamente mais radical de descrição e ideação do campo transcendental vivenciado pelo eu puro, mediante os diferentes níveis de redução. Para avaliar-se com rigor o alcance e os limites de tal programa de fundação transcendental não se podem ultrapassar indevidamente os parâmetros estritamente racionais que ele próprio estabelece. Se há lacunas no empreendimento sistemático assumido enquanto tal pelo próprio Husserl, elas devem ser apontadas e aprofundadas em consonância a instrumentos apropriados à aferição, ou seja, devem respeitar o circuito de instauração estipulado pelo autor, sob pena de cobrar-se dele um débito que não é seu, ou, pior ainda, tentar quitar a dívida com pagamento inadequado.

Atento a tais delimitações interpretativas, Nuno Nabais, em seu livro A evidência da possibilidade - A questão modal na fenomenologia de Husserl, ${ }^{6}$ procura pensar indiretamente as noções husserlianas de finito, infinito, horizonte e avaliar diretamente o conjunto do projeto husserliano, a partir das noções de possibilidade e de evidência. O procedimento rigorosamente descritivo da fenomenologia requer a convertibilidade das noções de possibilidade do fenômeno e de fenômeno da possibilidade, trazendo à evidência a estrutura intrínseca do campo transcendental. Intuir um objeto implica intuir simultaneamente seu horizonte de possibilidade. Nabais aponta, contudo, duas deficiências principais no desenvolvimento do programa husserliano: 1) "Husserl nunca procurou uma interpretação de conjunto do conceito de possibilidade, nem alguma vez tentou uma estratificação dos seus usos lógico, semântico, epistêmico ou ontológico" (Nabais, 1998, p. 14). 2) "Conceitos modais como os de possibilidade, efetividade, necessidade são transformados em objeto fenomenológico unicamente segundo a figura da 'crença' (Glaube). Para Husserl, toda a

6 Resultado de sua Tese de Doutorado, apresentada ao Departamento de Filosofia da Faculdade de Letras de Lisboa, em 1995. 
modalidade é uma 'modalidade de crença' (Glaubensmodalität)" (Nabais, 1998, p. 15). Como consequência, “... todas as modalidades dóxicas têm a sua origem no ato de percepção, ou melhor, no seu correlato dóxico, a 'certeza de crença' (Glaubensgewissheit)... Só a modalidade noética da certeza e a modalidade noemática da efetividade têm um valor primitivo" (Nabais, 1998, p. 17). Decorre daí a decisiva indagação do intérprete: "Como pensar então uma evidência da possibilidade que seja o domínio do esclarecimento da possibilidade da evidência se, no interior da teoria da crença, a única modalidade originária é a modalidade da efetividade?" (Nabais, 1998, p. 17-18). O intérprete concentra sua análise nos manuscritos de reformulação da Sexta Investigação Lógica, redigidos por Husserl entre 1911 e 1917, considerados cruciais para entender-se melhor o conceito husserliano de possibilidade. Conectando-os ao conjunto da obra do pensador alemão, detectam-se vários sentidos do conceito de possibilidade que passam gradativamente da esfera predicativa à esfera antepredicativa, encontrando nessa última seu estrato mais originário, sob a figura da potencialidade (Potentialität) enquanto possibilidade pura, elemento articulador e garantidor do programa fenomenológico husserliano em seu conjunto.

Embora não explorado diretamente por Nabais, talvez seja pertinente associar-se a noção de possibilidade pura ao conceito de "presente vivo e fluente" (lebendige strömende Gegenwart). No parágrafo 81 de Idéias I, Husserl já assumia de modo contundente que "o 'absoluto' transcendental, que nos preparamos por meio das reduções, não é, na verdade, o termo último, ele é algo que se constitui a si mesmo, em certo sentido profundo e inteiramente próprio, e que tem suas fontes originais num absoluto último e verdadeiro" (Husserl, 2006, p. 185). Absoluto derradeiro que ganha, a partir de Filosofia primeira, a enigmática denominação presente vivo e fluente. Cabe indagar: 1) Por que o privilégio do presente, mesmo na vigência estritamente transcendental? 2) Qual o papel das adjetivações, ou, de maneira mais precisa, que tipo de vida e de fluência operam neste âmbito absoluto? 3) Pode-se acessá-lo através dos procedimentos transcendentais intrínsecos à fenomenologia husserliana? 4) Atende ele às demandas fundacionais estabelecidas pelo próprio programa fenomenológico husserliano?

Para encaminhar respostas às duas primeiras perguntas, deve-se considerar que a presença do presente vivo e fluente não se opõe ao passado e ao futuro, nem cumpre o papel de impressão originária em relação às retenções e protenções. Trata-se antes de uma dinâmica pré e prototemporal de auto e heteropresentação transcendentais. A vivacidade e a fluência derivam do processo constitutivo incessante ali vigente, a partir do qual irrompem e se estruturam todos os horizontes visados 
pela reflexão fenomenológica. Se em um registro modal é indiscutível que Husserl privilegia o possível em relação ao efetivo, deve-se ressaltar que ambos se subordinam, juntamente com o necessário, às incessantes operações constitutivas do presente vivo, sendo permeáveis à apreensão fenomenológica somente a partir delas. Do mesmo modo, parece plausível dizer-se que apenas a partir de tais operações os horizontes infinitos, enquanto idéias em sentido kantiano, podem ser elucidados.

No tocante às duas últimas perguntas, cujas respostas se conectam de maneira decisiva, a dificuldade de encaminhamento é maior. Duas linhas interpretativas antagônicas merecem destaque: 1) A posição de Klaus Held, defendida, sobretudo, na obra Lebendige Gegenwart. Die Frage nach der Seinsweise des transzendentalen Ich bei Edmund Husserl, entwickelt am Leitfaden der Zeitproblematik; 2) A posição de Pedro Alves, exposta em especial no livro Subjectividade e tempo na fenomenologia de Husserl. Para Held, o programa fenomenológico husserliano torna impermeável per se o estatuto de seu fundamento último, ou seja, do presente vivo e fluente, decretando um incontornável obstáculo à pretensão de evidência total inerente ao programa. Há um resíduo de opacidade que subverte o projeto de translucidez e onisciência, e faz vacilar os próprios alicerces da empreitada fenomenológica. O argumento central desse diagnóstico negativo concerne à distância infranqueável entre o exercício de uma inspectio sui reflexiva radical e um irrefletido que sempre lhe escapa. O contato entre o visar reflexivo e o presente vivo desemboca em duas situações possíveis, ambas inaptas ao propósito de transparência fenomenológica: ou a reflexão apenas tangencia o non plus ultra fenomenológico, mantendo-o em sua integridade, porém não o apreendendo em sua instauração própria; ou a reflexão adentra na dinâmica constitutiva do limite fenomenológico, embora, em contrapartida, perca-o em sua originariedade, pois o mero influxo da visada reflexiva já o transforma e o apresenta de modo derivado.

Alves diverge da leitura restritiva de Held, propondo-se a "apresentar a pré-reflexividade não como limite externo, mas como conceito da própria reflexão" (Alves, 2003, p. 416). Isto significa considerar que o processo reflexivo radical não é produto do contato entre dimensões transcendentais já constituídas em qualquer nível, mas, ao contrário, que tais dimensões só se constituem precisamente mediante a reflexão fenomenológica. "A instauração desta posição do 'observador' de uma vida transcendental constituindo o mundo e nele aparecendo é o próprio acontecer da reflexão fenomenológica, sobrevindo pela inibição de toda a tese de ser e de todo o Seinsglauben" (Alves, 2003, p. 419). Tal instauração relacional do processo reflexivo radical rompe com toda opacidade e com toda distância entre os níveis transcendentais 
constitutivos, inviabilizando o sustentáculo da interpretação de Held. Liberado de tais óbices, o horizonte total de sentido torna-se passível de plena transparência. Tudo que se apresenta na reflexão fenomenológica, inclusive a dinâmica intrínseca do presente vivo nela constituída, pode ser apreendido em sua completude. Para tanto, basta entender-se que "É como reflexão sobre a reflexão que se abre a via de acesso ao Ego do lebendige Gegenwart" (Alves, 2003, p. 439).

Eis uma amostra relevante das opções interpretativas concernentes à questão dos limites intrínsecos e extrínsecos ao programa fenomenológico husserliano. Parece decisivo não imiscuir em tais pesquisas soluções estritas de caráter ético, em qualquer nível ou aspecto que seja. A questão deve ser pensada, sobretudo, no âmbito teórico, sistemático. As leituras de Nabais, Held e Alves atendem tais requisitos. A primeira estrutura-se a partir da noção de possibilidade e as demais em consonância à noção de presente vivo e fluente. Tais escolhas temáticas parecem colocar os comentários de Held e de Alves em um nível mais radical. Embora textualmente opostas, ao impor e liberar limites respectivamente, talvez se possa outorgar-lhes um desígnio comum: assumir a questão do infinito como a instância decisória do papel inerente à fenomenologia enquanto discurso sobre o fundamento, ou seja, enquanto filosofia primeira, em seu sentido mais digno e autêntico.

\section{Referências}

ALES BELLO, A. "Husserl interprete di Kant". In: Dialegesthai. Rivista telematica di filosofia [in linea], anno 7 [inserido em 07 de julho de 2005], disponível em <http:// mondodomani.org/dialegesthai/>, [91 KB], ISSN 1128-5478.

ALVES, P. Subjectividade e tempo na fenomenologia hussserliana. Lisboa: Centro de Filosofia da Universidade de Lisboa, 2003.

BARBERO, C. "Il problema dell'infinito nella fenomenologia di Husserl". In: Rivista di Estética, 15 (2000), p. 128-170.

CHESTOV, L. “Memento Mori”. In: Revue Philosophique, (1926): jan./fev., p. 5-62.

HELD, K. Lebendige Gegenwart. Die Frage nach der Seinsweise des transzendentalen Ich bei Edmund Husserl, entwickelt am Leitfaden der Zeitproblematik. Den Haag: Martinus Nijhoff, 1966.

HUSSERL, E. Ideen zur einer reinen Phänomenologie und phänomenologischen Philosophie. Zweites Buch: Phänomenologische Untersuchungen zur Konstitution. Edited by Marly Biemel. The Hague: Martinus Nijhoff, 1952.

Ideen zur einer reinen Phänomenologie und phänomenologischen Philosophie. Drittes Buch: Die Phänomenologie und die Fundamente der Wissenschaften. Edited by Marly Biemel. The Hague: Martinus Nijhoff, 1971.

. Ideen zu einer reinen Phänomenologie und phänomenologischen Philosophie. Erstes Buch: Allgemeine Einführung in die reine Phänomenologie. Edited by Karl Schuhmann. The Hague: Martinus Nijhoff, 1977. 
. Aufsätze und Vorträge (1911-1921), Husserliana XXV. Dordrecht-BostonLondon: Kluwer Academic Publishers, 1987.

Idéias para uma fenomenologia pura e para uma filosofia fenomenológica: introdução geral à fenomenologia pura. Tradução de Márcio Suzuki. Aparecida (SP): Idéias e Letras, 2006.

NABAIS, N. A evidência da possibilidade - A questão modal na fenomenologia de Husserl. Lisboa: Relógio D’Água, 1998. 